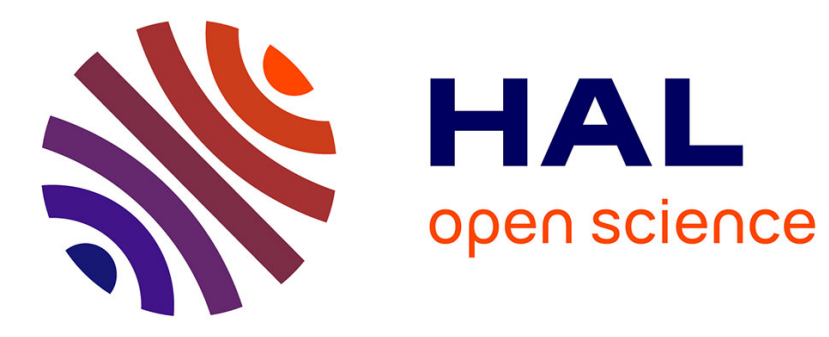

\title{
High-bandwidth transmission of an efficient photonic-crystal mode converter
}

Anne Talneau, Mario Agio, Costas M. Soukoulis, Mikael Mulot, Srinivasan Anand, Philippe Lalanne

\section{- To cite this version:}

Anne Talneau, Mario Agio, Costas M. Soukoulis, Mikael Mulot, Srinivasan Anand, et al.. Highbandwidth transmission of an efficient photonic-crystal mode converter. Optics Letters, 2004, 29 (15), pp.1745-1747. 10.1364/OL.29.001745 . hal-00874509

HAL Id: hal-00874509

https://hal-iogs.archives-ouvertes.fr/hal-00874509

Submitted on 18 Oct 2013

HAL is a multi-disciplinary open access archive for the deposit and dissemination of scientific research documents, whether they are published or not. The documents may come from teaching and research institutions in France or abroad, or from public or private research centers.
L'archive ouverte pluridisciplinaire HAL, est destinée au dépôt et à la diffusion de documents scientifiques de niveau recherche, publiés ou non, émanant des établissements d'enseignement et de recherche français ou étrangers, des laboratoires publics ou privés. 


\title{
High-bandwidth transmission of an efficient photonic-crystal mode converter
}

\author{
A. Talneau \\ Centre National de la Recherche Scientifique/Laboratoire de Photonique et de Nanostructures, \\ Route de Nozay, F-91460 Marcoussis, France \\ M. Agio \\ Istituto Nazionale per la Fisica della Materia, Dipartimento di Fisica “A. Volta," Università di Pavia, via Bassi, 6, I-27100 Pavia, Italy
}

C. M. Soukoulis

Research Center of Crete, IESL-FORTH, Heraklion, Crete, Greece

M. Mulot and S. Anand

Department of Microelectronics and Information Technology, Royal Institute of Technology, S-164 40 Kista, Sweden

\author{
Ph. Lalanne
}

Centre National de la Recherche Scientifique, Laboratoire Charles Fabry, B.P. 147, F-91403 Orsay, France

Received December 24, 2003

\begin{abstract}
We have investigated both theoretically and experimentally the spectral behavior and the transmission and reflection performance of a photonic-crystal $(\mathrm{PhC})$ mode converter upon an InP substrate. This taper exhibits $70 \%$ transmission efficiency on an 80-nm bandwidth when it couples a ridge access guide to a strongly confined single-missing-row $\mathrm{PhC}$ guide. Such a taper design included in a $\mathrm{PhC}$ bend contributes a large benefit to the overall transmission budget of the PhC-based link. () 2004 Optical Society of America
\end{abstract}

OCIS codes: $130.0130,130.2790$.

Two-dimensional photonic-crystal-based guiding structures are attractive for integrated optics because of their specific mechanism of light confinement, ${ }^{1}$ which is expected to increase the integration of optical functions and the compactness of photonic integrated circuits. Working on InP-based material allows active functions to be used as emitters ${ }^{2,3}$ and amplifiers. Photonic-crystal $(\mathrm{PhC})$ waveguides $(\mathrm{PhCWs})$ can be obtained by removal of rows of holes in a perfect $\mathrm{PhC}$. Such linear defects can support propagating modes. A single-missing-row $\mathrm{PhCW}$, termed $\mathrm{W} 1$, is an interesting candidate for guided optics, as it may support a single, even mode for properly chosen frequency domains. However, this strongly laterally confined structure will suffer from poor coupling to any classic guiding structure. For membrane-type structures, efficient access was recently proposed. ${ }^{4}$

Operating with an InP substrate, any mode within the gap always propagates above the light cone; also, the low vertical index contrast (GaInAsP versus InP) results in wide spreading of the mode. We previously proposed for this environment a PhC mode converter based on a gradual variation of hole size and depth. ${ }^{5}$ This mode converter allows the guided mode to be transferred from a wide and multimode $\mathrm{PhCW}$ to the strongly confined W1 structure. Multimode PhCWs have a specific spectral feature that is already well characterized and comes from the contradirectional coupling between modes that is due to the PhC's corrugations on both sides. ${ }^{6}$ These mini stop bands correspond to a frequency domain where the transmission is strongly affected.

Here we investigate the spectral behavior of the taper. The plane-wave expansion method is used for dispersion diagram calculation. Measurements of straight structures with and without tapers are reported for the two reduced frequency domains in which W1 is monomode. Reduced frequency $u$ is defined as the ratio $u=a / \lambda$, where $a$ is the $\mathrm{PhC}$ period and $\lambda$ is the wavelength. Also, the efficient taper operation calculated in Ref. 5 on a W3 (three missing rows)-W1 bend is demonstrated here on a 20-nm bandwidth for a double-bend structure.

$\mathrm{PhCW}$ are fabricated upon a two-dimensional $\mathrm{PhC}$ consisting of a triangular array of holes drilled in a 500-nm-thick GaInAsP confining layer. These holes are etched by chemically assisted ion beam etching by $\mathrm{Ar} / \mathrm{Cl}_{2}$ chemistry. ${ }^{7}$ The typical etched depth is larger than $3 \mu \mathrm{m}$ for an air-filling factor $f=40 \%$. For the purpose of external source measurement, and for a reproducible coupling of the light into and out of the $\mathrm{PhC}$ section, the PhCW is inserted between two monomode ridge access guides limited by cleaved facets. ${ }^{8}$ For proper width of the access ridges, the transmission from the ridge to $\mathrm{PhCW}$ W3 is greater than $90 \%$ in a wide spectral range. ${ }^{8}$ The taper section reduces the PhCW from W3 to W1, as is visible in Figs. 1(a) and 1(c). Figure 1(a) corresponds to the fabrication of a 


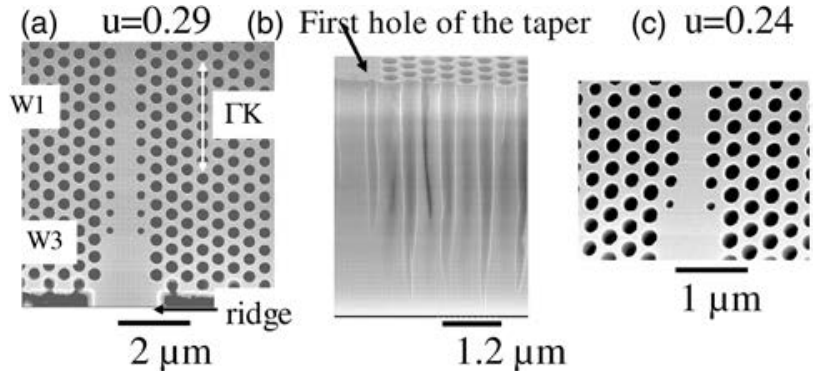

Fig. 1. Photographs of the taper. Left, center, $u=0.29$ : (a) top view, (b) cross view. Right, $u=0.24$ : (c) top view.

10-row-long taper in the $u=0.29$ frequency domain, and Fig. 1(c) corresponds to a 4-row-long taper in the $u=0.24$ frequency domain. As simulated in Ref. 9, the taper can be very short, provided that the first hole is very small (diameter less than $100 \mathrm{~nm}$ ).

Measurements are performed in TE polarization, on a 1410-1590-nm wavelength span covered by two polarization-maintained output-tunable laser sources. The $u=0.29$ domain corresponds to a $\mathrm{PhC}$ period of $a=450 \mathrm{~nm}$ and to air holes of 300-nm diameter for an air-filling factor $f=40 \%$. The smallest hole that we were able to fabricate is the first one that is visible by chance in the cleaved cut of Fig. 1(b). Its diameter is $180 \mathrm{~nm}$, much larger than what would ensure correct transmission through the taper. We optimized the $\mathrm{PhC}$ fabrication process, and the first hole of the four-row-long taper investigated in the $u=0.24$ domain has a 100 -nm diameter.

We have investigated two reduced frequency domains in which PhCW W1 is monomode: $u=0.29$ and $u=0.24$ above and below the odd mode. These domains are marked on the dispersion diagram of $\mathrm{W} 1$ presented in Fig. 2(a) for an air-filling factor $f=40 \%$. Figure 2(b) presents the dispersion diagram of $\mathrm{PhCW}$ W3 for the same filling factor. In the $u=0.27$ domain, one mini stop band exists that affects the fundamental even-mode transmission; another one affects the second even mode. Although our vertical structure is nonsymmetric, we can consider that we are close to a perfect $\mathrm{PhCW}$ for which no coupling should occur between modes of different parity, although crossing of even modes and odd modes should not affect the transmission. We now consider the PhCW sections within the taper where the holes of the first inner row are reduced. For the taper of Fig. 1(a), the first hole has a $180-\mathrm{nm}$ diameter, which corresponds to a $40 \%$ reduction with respect to the matrix hole size. Going from the ridge access along the taper, the light experiences a true $\mathrm{W} 3$, then a W1 with a $40 \%$ reduced first row, then smaller reductions $(-30 \%$, $-20 \%)$ to reach the true W1 waveguide. We have plotted in Figs. 2c1-2c3 the band diagrams for these specific $\mathrm{W} 1$ waveguides. When the inner holes grow from $-40 \%$ to $-20 \%$, one can clearly see the mini stop band moving up from $u=0.29$ to $u=0.31$. No such mini stop band exists in the $u=0.24$ domain: neither for W3 nor for reduced W1. In this frequency domain, only one additional odd mode exists, but no power should be coupled to it.
To investigate the taper's spectral behavior we fabricated samples including PhCWs W1 of different lengths $(25-150 \mu \mathrm{m})$ between two ridge access guides ${ }^{8}$ with and without a taper at the ridge-W1 transition, for the two frequency domains $u=0.29$ and $u=0.24$. We report here the results for a 50- $\mu \mathrm{m}$-long W1 section.

For all the structures in the $u=0.28-0.30$ domain, $f=40 \%$, the transmission without a taper is poor but constant in the entire wavelength domain [Fig. 3(a), left]. Including the taper [Fig. 3(b), left], one can see an improved transmission in the $u=0.28$ $(\lambda=1500 \mathrm{~nm})$ domain but a strong reduction in the 1440 -nm domain $(u=0.30)$ when one is approaching the band edge at the $\Gamma$ point $(k=0)$. This reduced transmission is caused by the mini stop bands of the W1-reduced $\mathrm{PhCW}$ that altogether cover the spectral span from $u=0.29$ to $u=0.30$.

In the $u=0.24$ domain the spectral behavior depends strongly on air-filling factor $f$; an interesting (a) W1

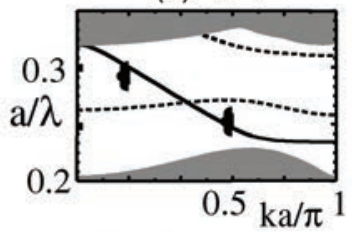

(b) W3
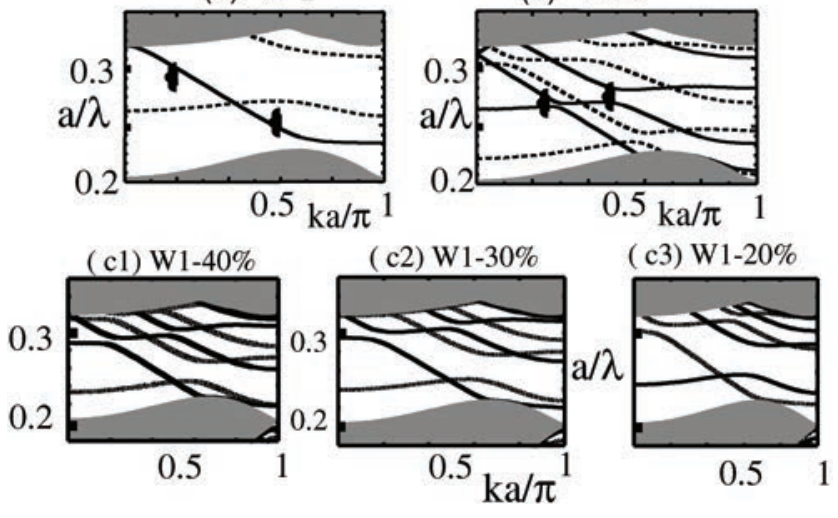

Fig. 2. Dispersion diagrams of a $\mathrm{PhC}$ waveguide $\mathrm{W} 1$ and a $\mathrm{PhC}$ waveguide W3 for $f=40 \%$ along the $\Gamma K$ direction; the two frequency domains investigated, near $u=0.29$ and $u=0.24$, are marked by braces. (c1)-(c3) Dispersion diagrams for a W1 when the radii of the holes of the inner row are reduced.

(a)
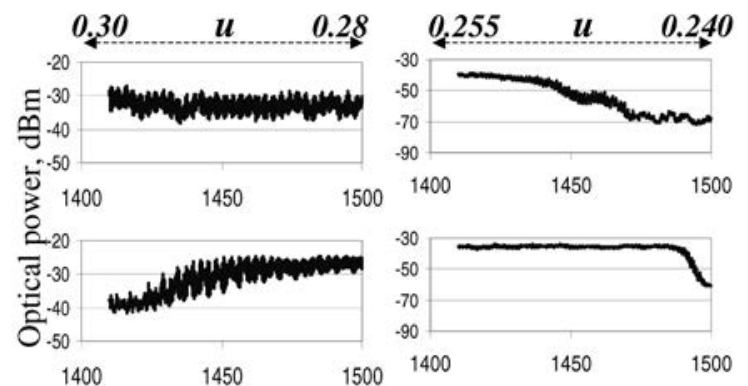

(c)
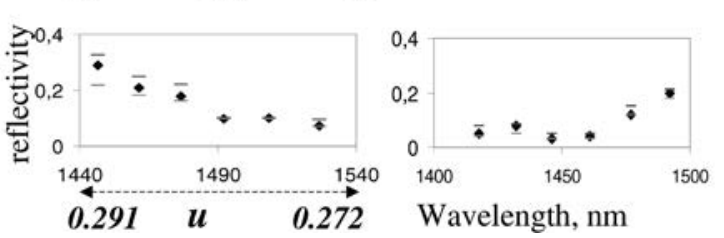

Fig. 3. Transmission spectra through $\mathrm{PhCW}$ W1: left, $u=0.29(f=40 \%)$; right, $u=0.24(f=34 \%)$. (a) Without a taper, (b) including a taper, (c) spectral reflectivity of the taper. 
(a)

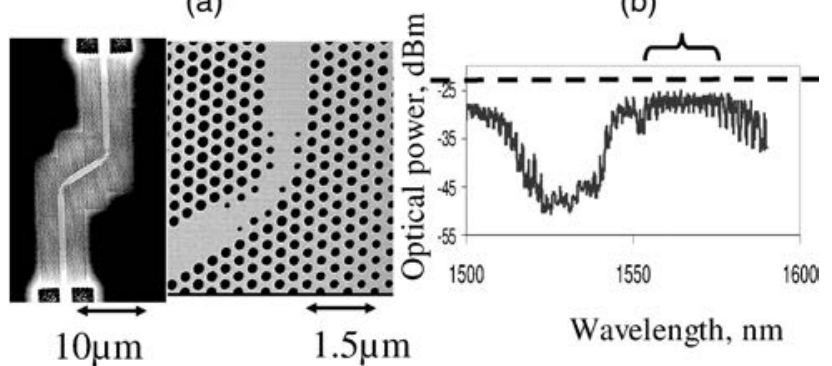

Fig. 4. (a) Photographs of a W3-W1 tapered double bend. Left, the general structure; right, a detailed tapered bend. (b) Spectral transmission of the tapered double bend; the mean transmission of the deep ridge is plotted (dashed line) as a reference.

example is for $f=34 \%$. Without a taper [Fig. 3(a), right] the transmission is strongly affected when it reaches the mode cutoff at $k=\pi / a$. When a taper is included, the transmission is slightly increased near $u=0.255(\lambda=1420 \mathrm{~nm})$ and is much more strongly increased near $u=0.245(\lambda=1480 \mathrm{~nm})$ when it approaches the mode cutoff, which here is sharp. We propose that, without a taper, the lateral spreading of the $\mathrm{W} 1$ mode in the $u=0.245$ domain results in strong scattering at the abrupt transition ridge-W1 owing to the severe modal mismatch and drastically reduces the transmission. The taper clearly operates an adiabatic transition that funnels the light from the ridge mode onto the W1 even mode and permits a sharp mode cutoff at band edge $k=\pi / a$.

For both $u$ domains we measured the spectral reflectivity of the taper plotted in Fig. 3(c). The result for $u=0.29$ was already proposed in Ref. 10 and is reproduced here merely for comparison. The large reflectivity measured in the $u=0.29$ domain is directly due to the light that is backcoupled via the mini stop bands. In the $u=0.24$ domain, because there is a small first hole, the taper's reflectivity is below $1 \%$ on a wavelength span as large as $80 \mathrm{~nm}$. As soon as we approach mode cutoff, the reflectivity increases, as the taper design does not handle the large lateral spreading of the mode in this slowing-down region. The taper transmission is as high as $70 \%$ in the $80-\mathrm{nm}$ wavelength domain. We obtained this figure by measuring PhCW W1s of several lengths.

As a conclusion, we can say that the taper is highly efficient when the mode is mainly refractivelike and does not operate properly on slow modes (mini stop bands or cutoff domains).

Simulations reported in Ref. 5 have shown the advantage of using a tapered bend to reach a large overall transmission between wide $\mathrm{PhC}$ guides. Such a tapered bend has been included in a double-bend structure in the $u=0.24$ domain, as is visible in the photograph of Fig. 4(a). At the left is a general view of the W3-tapered W1 double bend. Such a bend design will provide several advantages: correct matching between the ridge access guide and the large $\mathrm{PhCW}$ W3, low propagation losses in the straight $\mathrm{PhCW}$ sections, and no polarization conversion in the
W1 bend. ${ }^{11}$ The measured spectral transmission of such a double bend is plotted in Fig. 4(b); we have included here as a reference the mean level of the transmission through a deep ridge of the same total length. The ridge transmission level is $-24 \mathrm{dBm}$ (dashed line); the 4- $\mathrm{dB}$ contrast of the ridge fringes is omitted for clarity. As the W3 sections are short, we can say that on a large bandwidth (1557-1575 nm) the tapered double bend demonstrates an overall transmission budget of $-27 \mathrm{dBm}$, which is only $3 \mathrm{~dB}$ below the straight ridge and is much larger than the $-32-\mathrm{dBm}$ overall transmission reached with a fully W1-based PhCW double bend (not plotted here). Looking carefully at the photograph [Fig. 4(a)], one can see that there is room for improvement in the fabrication, which would lead to even better results.

The spectral behavior of a photonic-crystal taper has been experimentally determined and clearly related to the contribution of mini stop bands calculated for the wide $\mathrm{PhC}$ waveguides involved in its design. In a frequency domain that is free from mini stop bands, the taper exhibits a flat transmission of $70 \%$ on a bandwidth as large as $80 \mathrm{~nm}$ (limited by the mode cutoff). A wide $\mathrm{PhCW}$ double bend including this specific taper design for both bends demonstrates only 3-dB additional losses compared with a straight deep ridge. Such a design confirms that a full photonic-crystal taper should be useful for future compact PhC-based photonic integrated circuits.

A. Talneau's e-mail address is anne.talneau@ lpn.cnrs.fr.

\section{References}

1. J. D. Joannopoulos, R. D. Meade, and J. N. Winn, Photonic Crystals (Princeton U. Press, Princeton, N.J., 1995).

2. M. Kamp, T. Happ, S. Mahnkopf, A. Forchel, S. Anand, and G. H. Duan, presented at the 29th European Conference on Optical Communication, Rimini, Italy, September 21-25, 2003.

3. A. Talneau, M. Mulot, and S. Anand, presented at the 29th European Conference on Optical Communication, Rimini, Italy, September 21-25, 2003.

4. S. J. McNab, N. Moll, and Y. A. Vlassov, Opt. Express 11, 2927 (2003), http://www.opticsexpress.org.

5. A. Talneau, Ph. Lalanne, M. Agio, and C. M. Soukoulis, Opt. Lett. 27, 1522 (2002).

6. S. Olivier, M. Rattier, H. Benisty, C. Weisbuch, C. J. M. Smith, R. M. De La Rue, T. F. Krauss, R. Houdré, and U. Oesterle, Phys. Rev. B 63, 113311 (2001).

7. M. Mulot, S. Anand, C. F. Carlström, M. Swillo, and A. Talneau, Phys. Scr. T101, 106 (2002).

8. A. Talneau, L. Legouezigou, and N. Bouadma, Opt. Lett. 26, 1259 (2001).

9. Ph. Lalanne and A. Talneau, Opt. Express 10, 354 (2002), http://www.opticsexpress.org.

10. A. Talneau, M. Mulot, S. Anand, and Ph. Lalanne, Appl. Phys. Lett. 82, 2577 (2003).

11. A. Talneau, M. Mulot, S. Anand, S. Olivier, M. Agio, M. Kafesaki, and C. M. Soukoulis, "Modal behaviour of single-line photonic crystal guiding structures on InP substrate," Photonics Nanostruct. Fundamentals Applications (to be published). 